Business programs require a strong element of the social sciences and the best ones include a consideration of ethics. Too often, humanities scholars are content to stick to their narrow disciplines-they must convince others of the relevance of their expertise. If general education and creative thinking are to become part of the curriculum, expertise in the humanities and social sciences is absolutely necessary.

Several key challenges are evident: to improve the image of the soft sciences at every university; to provide capacity in a country to educate scholars at a high level in the various soft science disciplines (all universities of course need not offer a full range of specialties); to integrate the humanities and social sciences into interdisciplinary programs in professional and other fields; and to have capacity in these fields to contribute to general education.

The humanities and social sciences are not only an essential part of the idea of the university; they are at the core of understanding contemporary society. History, sociology, philosophy, and other disciplines interpret today's key challenges. The university, as the central institution providing careful analysis and interpretation of society, requires the soft sciences as never before.

\section{Exploring Academic Salaries in a Comparative Context}

\section{IVán Pacheco and laura E. Rumbley}

Iván Pacheco is a graduate research assistant and doctoral student in higher education administration at Boston College. Laura E. Rumbley is a research associate at the Boston College Center for International Higher Education.E-mails: pacheciv@bc.edu; rumbley@bc.edu.

U urveying the range of faculty salaries around the world feels like checking out apples and oranges .... and bananas, strawberries, kiwis, cherries, and plums. Finding complete, current, and parallel sets of data across countries often represents an extraordinarily difficult task. It becomes even more daunting to compare the data in various countries against one another, given the unique cultural, economic, and professional circumstances in which academics live and work across the globe.

Examining faculty compensation around the world can reveal the value individual societies attribute to the academic enterprise and those who carry it forward. This work can highlight the factors that affect how academic staff are compensated in different countries. And, it may also add much-needed insight into the phenomena of brain drain and brain gain.

A small number of studies have attempted to compare fac- ulty salaries internationally, but only a few have cast a wide geographic net and included countries of varied levels of national and economic development. In 2007, the Boston College Center for International Higher Education (CIHE) launched an exploratory project attempting to do just thatcollecting and comparing salary data (in World Bank PPP dollars) from I5 countries and one territory, including Argentina, Australia, Canada, China, Colombia, France, Germany, India, Japan, Malaysia, New Zealand, Saudi Arabia, South Africa, the United Kingdom, the United States, and Palestine.

In terms of salary progressions over the course of a career, our data show that faculty in wealthier, more developed countries tend to enjoy greater potential for salary growth.

\section{Salary Comparisons and National Development}

The CIHE study found that overall average monthly salaries ranged from $\$ \mathrm{I}, \mathrm{I} 82$ in China to $\$ 6,038$ in Canada. These findings produced an international average of $\$ 4,856$ per month, with Canadian academics earning on average 5.I times more on a monthly basis than their Chinese counterparts.

To put some of this information in context, it is important to consider how faculty salaries compare to some benchmark data. Here, we looked at target countries' relative positions on the Human Development Index (HDI) of the United Nations Development Program for comparative analysis. Not surprisingly, the countries of less advanced "human development" exhibited lower average salaries than those considered to have higher levels of human development.

There were several interesting exceptions to this rule, however. For example, Saudi Arabia, ranked no. 6I on the HDI, consistently outpaced average salary levels in Australia (no. 3), the United Kingdom (no. I6), Japan (no. 8), Germany (no. 22), and France (no. Io). South Africa also bucked this trend to some degree. With an HDI ranking of I2I, South Africa registered a higher entry-level salary average than Malaysia (no. 63), Colombia (no. 75), and China (no. 8I). Even more notable, in a comparison of top-level salary averages, South Africa showed higher levels of compensation than Io of the I5 countries studied-including Australia, the United Kingdom, Japan, Germany, and France. Meanwhile, the Chinese higher education system consistently came in dead last in the international comparison of salary averages.

\section{Earnings Potential Over Time}

In terms of salary progressions over the course of a career, our data show that faculty in wealthier, more developed countries tend to enjoy greater potential for salary growth. However, here again notable exceptions occurred to this trend. South Africa 
came out just behind the United States and Canada as the country with the third-largest spread from entry- to top-level salaries. Thus, in absolute terms, South African academics can expect to grow their salaries more robustly over the course of their careers than those in Australia, New Zealand, Japan, the United Kingdom, Germany, or France. Meanwhile, when looking at salary progressions over time, an even larger number of developing countries outpace wealthier nations. China, South Africa, Malaysia, and Colombia all register salary increases of over roo percent over the course of a career. Indeed, the data for China suggest the potential for academics to grow their salaries over I70 percent from entry- through top levels on the academic employment ladder, with salary increases for German and France hovering at just around 39 and 32 percent, respectively.

\section{ACademic Salaries and National income Averages}

Comparing faculty salaries to average per capita-income estimates indicates that the academic profession pays well in many parts of the developing world. In India, for example, average faculty salaries are a whopping 8.7 times greater than that country's average World Bank GDP monthly per capita estimate. On average, South African and Colombian academics make salaries 5.8 and 5.4 times greater, respectively, than their countries' GDP per capita figures. In contrast, more developed countries-like the United States, Australia, Japan, the United Kingdom, France, Germany, Canada, and New Zealand-present faculty incomes that are only I.4 to 2.2 times above their country's GDP per capita-per month figures.

These findings highlight different kinds of issues for the world's less-developed and more highly developed countries.

\section{POLICY I M PLICATIONS}

These findings highlight different kinds of issues for the world's less-developed and more highly developed countries. The CIHE study indicates that faculty in at least some lessdeveloped countries are not poorly compensated in comparison with their own national GDP per capita-income estimates. However, a global market for talent means that more competitive salary packages may be necessary to compete with overseas employment offers. If not, brain drain will continue to beleaguer many already struggling poorer nations.

Meanwhile, while it is true that faculty in "high human development" countries enjoy better salaries on average than their colleagues in other parts of the world, our GDP comparison exercise indicates that the academic salaries in more developed countries are not much higher than their average per capita-income estimates. In countries where an egalitarian approach to remuneration across society is an important cul- tural norm, this trend may not be an issue. But in contexts in which academics may find themselves earning an "average" salary following many more years of schooling than the average citizen-or making far less than other professionals (for example, in the legal, medical, or high technology fields) - it may be difficult to retain top talent in higher education. Of course, this study does not compare faculty salaries with those of other professions, and more work in this area clearly needs to be done.

\section{A Research Agenda}

Meaningful comparative analysis of faculty salaries requires more and better data on compensation and the application of interdisciplinary expertise to make good sense of the financial, economic, and contextual variables. At the same time, the development of an academic purchasing power parity tool-a "professor's basket of goods," if such a thing could be craftedmight provide a much more relevant way to reflect how salaries relate to the needs, expenses, and lifestyles of the academics who receive them. Future research in this area needs to address the salary realities of growing numbers of part-time faculty; must compare income across academic disciplines; and should include a comparison to the salaries earned by other highly trained professionals within and across countries.

\section{CONCLUSION}

Both merit and interest are provided in understanding how faculty are compensated around the world. Universities and the highly qualified academics who staff them play a key role in helping nations achieve and maintain a competitive position in a global marketplace of economic activities and ideas. Given this simple reality, faculty salaries stand out as a subtle but important consideration in any national development conversation and in the race for international relevance.

\section{Research Careers: Some Reflections from Europe}

\section{Ulrich Teichler and Harald Schomburg}

Ulrich Teichler is professor at the International Centre for Higher Education Research, University of Kassel, 34109 Kassel, Germany. E-mail: teichler@incher.uni-kassel.de. Harald Schomburg is a researcher at the International Centre for Higher Education Research. E-mail: schomburg@incher.uni-kassel.de.

Tn Europe, extension in the number of researchers and Iimprovement of research quality are widely seen as necessary to cope with the challenges expressed by the terms 